\title{
Zoonotic vaccinia virus strains belonging to different genetic clades exhibit immunomodulation abilities that are proportional to their virulence
}

\author{
Karine Lima Lourenço ${ }^{1}$, Leandro Andrade Chinália' ${ }^{1}$, Lethícia Ribeiro Henriques²,
} Rodrigo Araújo Lima Rodrigues ${ }^{3,4}$ and Flávio Guimarães da Fonseca ${ }^{1 *}$ (1)

\begin{abstract}
Background: The vaccinia virus (VACV) isolates, Guarani P1 virus (GP1V) and Passatempo virus (PSTV), were isolated during zoonotic outbreaks in Brazil. Each one of them belongs to two different VACV clades, defined by biological aspects that include virulence in mice and phylogenetic analysis. Considering that information about how vaccinia viruses from different groups elicit immune responses in animals is scarce, we investigated such responses in mice infected either by GP1V (group 2) or PSTV (group 1), using VACV Western Reserve strain (VACV-WR) as control.
\end{abstract}

Methods: The severity of the infections was evaluated in BALB/C mice considering diverse clinical signs and defined scores, and the immune responses triggered by GP1V and PSTV infections were analysed by immune cell phenotyping and intra-cytoplasmic cytokines detection.

Results: We detected a reduction in total lymphocytes (CD3 +), macrophages (CD14+), and NK cells (CD3-CD49+) in animals infected with VACV-WR or GP1V. The VACV-WR and GP1V viruses, belonging to the most virulent group in a murine model, were able to down-modulate the cell immune responses upon mice infection. In contrast, PSTV, a virus considered less virulent in a murine model, showed little ability to down-modulate the mice immune responses. Mice infected with VACV-WR and GP1V viruses presented significant weight loss and developed lesions in their spleens, as well as damage to liver and lungs whereas mice infected with PSTV developed only moderate clinical signs.

Conclusions: Our results suggest that VACV immunomodulation in vivo is clade-related and is proportional to the strain's virulence upon infection. Our data corroborate the classification of the different Brazilian VACV isolates into clades 1 and 2, taking into account not only phylogenetic criteria, but also clinical and immunological data.

Keywords: Poxvirus, Vaccinia virus, Immune response, Immune downmodulation, Guarani P1 virus, Passatempo virus

\footnotetext{
*Correspondence: fdafonseca@icb.ufmg.br

${ }^{1}$ Laboratory of Basic and Applied Virology, Department of Microbiology,

Institute of Biological Sciences, Federal University of Minas Gerais, Belo Horizonte, MG, Brazil

Full list of author information is available at the end of the article
}

\begin{abstract}
Background
Members of the Poxviridae family present a doublestranded DNA genome that varies from 140 to $300 \mathrm{kbp}$ in size, depending on the virus species. Their large genomes encode more than 150 genes, including some involved in immunomodulatory mechanisms [1-3]. In Brazil, vaccinia virus (VACV) has been circulating in rural and wild environments for decades[4]. Brazilian VACV isolates are
\end{abstract} original author(s) and the source, provide a link to the Creative Commons licence, and indicate if changes were made. The images or other third party material in this article are included in the article's Creative Commons licence, unless indicated otherwise in a credit line to the material. If material is not included in the article's Creative Commons licence and your intended use is not permitted by statutory regulation or exceeds the permitted use, you will need to obtain permission directly from the copyright holder. To view a copy of this licence, visit http://creativecommons.org/licenses/by/4.0/. The Creative Commons Public Domain Dedication waiver (http://creativeco mmons.org/publicdomain/zero/1.0/) applies to the data made available in this article, unless otherwise stated in a credit line to the data. 
currently classified into two groups: group 1 (less virulent in a murine model of infection), and group 2 (more virulent in a murine model of infection) (Fig. 1). In addition to virulence in mice, this division reflects biological properties of the isolates such as plaque phenotype in BSC-40 cells and genetic differences, including the presence or absence of an 18 nucleotide deletion in the viral hemagglutinin protein (HA A56R) coding gene (see inset on Fig. 1) [5].

The Guarani P1 virus (GP1V) and Passatempo virus (PSTV), used in this study, were isolated in Minas Gerais, Brazil, in 2001 and 2003 respectively, from outbreaks in rural properties involving cattle and humans $[6,7]$. The infections by these viruses caused lesions on the udder, teats, snout and oral mucosa of cows and calves. Milkers usually develop hand lesions after unprotected contact with cows infected with these viruses and clinical signs such as high fever, severe headache, back pain and lymphadenopathy are frequently reported by individuals handling infected cows $[7,8]$.

Much of the replicative success of poxviruses is related to their capacity to obstruct, escape or subvert essential elements of their host's antiviral responses. It has been proposed that the poxviruses' ability to down-modulate the host's immune response is directly proportional to their virulence in vivo [9]. Previous studies have already shown a difference in the modulation of the immune response in mice infected with non-replicating (Modified vaccinia virus Ankara), attenuated (vaccinia virus Lister), and replicative (vaccinia virus Western Reserve) virus strains $[9,10]$.

The evaluation of infections caused by naturally circulating VACV strains GP1V (group 2) and PSTV (group 1) represents an opportunity to analyse immune responses triggered in the host as a result of infections with viruses presenting different virulence patterns. Such studies can, then, be compared to those including either laboratory strains of VACVs or vaccine strains. Here we investigated the immune responses triggered in BALB/c mice infected with the GP1V or PSTV VACV strains, originated from zoonotic outbreaks in Brazil, compared to infections by a laboratory reference strain, vaccinia virus Western Reserve (VACV-WR). Our results are important not only to better define patterns of immunomodulation in vivo,

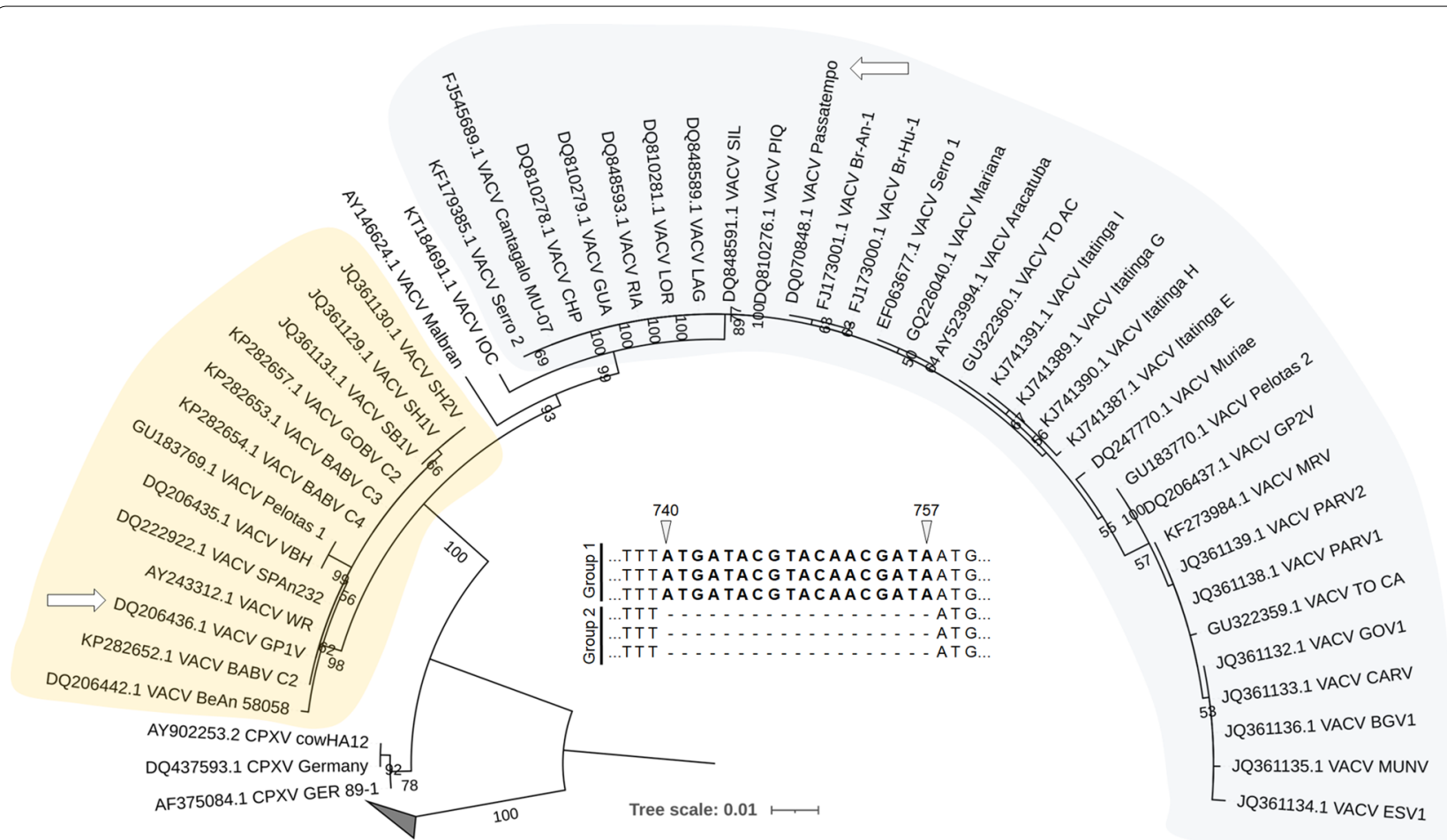

Fig. 1 Phylogenetic analysis of VACV-BR based on nucleotide sequences of the A56R gene (hemagglutinin). VACV-BR group 1 is highlighted with light yellow and group 2 with light blue. White arrows indicate the Brazilian viruses used in this study. The alignment was built using Muscle with standard parameters [45]. The maximum likelihood tree was built with IQ-TREE [46]. The best-fit replacement model selected by ModelFinder was $\mathrm{HKY}+\mathrm{F}+\mathrm{I}$. The branch supports were estimated using 1000 replicates of standard bootstrap and the tree was visualized with iTOL [47]. Bootstrap values lower than 50 were suppressed. The clade of variola viruses has been collapsed. The scale bar indicates the number of substitutions per site. A schematic alignment was included (inset) to indicate the genomic signature that divides VACV-BR into two distinct groups, an 18-nt deletion between positions 740 and 757 of the A56R gene. The representation was based on the VACV-WR (AY243312) gene 
caused by zoonotic vaccinia viruses, but they also corroborate the genetic classification of feral VACVs into two separate clades, which has been subject of criticism.

\section{Methods \\ Viruses}

Samples of GP1V and PSTV strains were kindly provided by Dr. Erna Kroon (Universidade Federal de Minas Gerais, Belo Horizonte, Brazil) and VACV-WR was gently provided by Dr. Bernard Moss (NIAID/NIH, Bethesda, EUA). The three viral samples were grown and titrated (PFU/ml) in BSC-40 cells through plaque assay and purified in sucrose cushions, as described before [11].

\section{Infection of mice and clinical signs}

$\mathrm{BALB} / \mathrm{c}$ mice used in this study were obtained from UFMG's central animal facility (Belo Horizonte, Brazil) and maintained in our experimental animal facility (Departamento de Microbiologia, Belo Horizonte, Brazil). Animals were kept into ventilated cages with food and water ad libitum. All in vivo procedures were approved by the Committee of Ethics for Animal Experimentation (CETEA) from UFMG, under permission 9/2019. Six-week-old male mice were separated into groups infected with GP1V, PSTV, VACV-WR or mockinfected (control). Animals were anaesthetized by intraperitoneal injection of ketamine and xylazine $(70 \mathrm{mg} /$ $\mathrm{kg}$ and $12 \mathrm{mg} / \mathrm{kg}$ of body weight in phosphate-buffered saline [PBS], respectively). The intranasal (i.n.) route was used to inoculate $10 \mu \mathrm{L}$ of PBS or $10 \mu \mathrm{L}$ of purified viruses diluted in PBS on subgroups of five animals each (for clinical signs and weight loss evaluation) or subgroups of seven animals each (histopathological analysis, splenocyte preparation, immunophenotyping and detection of intracellular cytokines).

In order to monitor infections from a clinical perspective, groups of five animals each were inspected daily, starting from the inoculation day. Inoculums of $10^{4}, 10^{5}$ and $10^{6}$ PFU of PSTV, VACV-WR or GP1V were used to infect the animals whilst the control group was inoculated with sterile PBS. Weight loss and clinical signs were evaluated for 10 days and registered.

\section{Histopathological analysis}

Seven days post inoculation of $10^{6}$ PFUs of GP1V, PSTV, VACV-WR or PBS, animals were euthanized and had spleens, lungs and livers harvested for histopathological analysis. Fragments of organs were fixed with formalin for $24 \mathrm{~h}$ and dehydrated with increasing concentrations (from 70 to $100 \%$ ) of ethanol. Tissue fragments were diaphanized in xylol and embedded in paraffin. The segments were sectioned in a microtome $(5 \mu \mathrm{m})$ and stained using Hematoxylin and Eosin. A pathological characterization of these slide preparations was performed, through the attribution of clinical scores, considering the presence and distribution of inflammation, edema, pulmonary hemorrhage and inflammation along with hepatic and splenic reactive degeneration [12-14].

\section{Splenocyte preparation, immunophenotyping and detection of intracellular cytokines}

In order to evaluate the production of interferon- $\gamma$ (IFN$\gamma)$ and tumor necrosis factor $\alpha$ (TNF- $\alpha$ ) by CD $4+$ and $\mathrm{CD} 8+\mathrm{T}$ lymphocytes, mice were inoculated with $10^{6}$ PFUs of PSTV, GP1V or VACV-WR through the intranasal route. Their spleens were harvested 7 days post infection and the splenocytes were obtained after tissue maceration. For erythrocyte lysis, cell extracts were resuspended in deionized water and incubated on ice. PBS 10X was used to stop the lysis process. Cell proliferation assays were performed through splenocyte labelling with Bromodeoxyuridine (BrdU). 96-well plates containing $2 \times 10^{5}$ spleen cells per well received stimulus of $10^{4}$ PFU of purified, UV-inactivated VACV-WR; concanavalin A (ConA); or just RPMI medium (Gibco, Carlsbad, USA). Plates were incubated at $37{ }^{\circ} \mathrm{C}$ in a $5 \% \mathrm{CO}_{2}$ atmosphere for $72 \mathrm{~h}$. The evaluation of cell proliferation was performed according to the BrdU Cell Proliferation Assay kit (Millipore, USA) manufacturer's instructions. For cell immunophenotyping, 96-well plates containing $2 \times 10^{5}$ splenocytes per well were cultivated and incubated for $30 \mathrm{~min}$ at $4{ }^{\circ} \mathrm{C}$, in the dark, with monoclonal antibodies. Cell surface markers CD4, CD8, CD19, CD3/CD49 and CD14, as well as the costimulatory molecules CD25, CD28, CD80 and CD86 were evaluated. Plates were washed with PBS, centrifuged and cells were suspended in $200 \mu \mathrm{L}$ of Macs Facs Fix (MFF) fixative solution.

For the purpose of detecting intracellular cytokines, $10^{7}$ cells extracted from the macerated spleens were stimulated overnight with UV-inactivated VACV-WR $\left(10^{4} \mathrm{PFU}\right)$ and incubated for $4 \mathrm{~h}$ at $37^{\circ} \mathrm{C}$ with Brefeldin A (Sigma, MO, USA) at $1 \mathrm{mg} / \mathrm{ml}$. Cells were washed in FACS buffer and stained with anti-CD4 and anti-CD8 antibodies (BD Pharmingen, NJ, USA) for $30 \mathrm{~min}$ at $4{ }^{\circ} \mathrm{C}$ in the absence of light. Cells were permeabilized with FACS buffer containing $0.5 \%$ saponin, and then stained with mouse anti-TNF- $\alpha$, anti-IFN- $\gamma$, anti-Interleukin 4 and anti-Interleukin 10 (BD Pharmingen, NJ, USA) for further $30 \mathrm{~min}$ at room temperature. A new washing step with FACS buffer containing $0.5 \%$ saponin was followed by two washes with FACS buffer only. Cell preparations were stored at $4{ }^{\circ} \mathrm{C}$ in the dark after fixation using FACS fix solution. A FACSCalibur cytometer (Becton, Dickinson, NJ, USA) was used for flow cytometry, and further analyses were performed using FlowJo software-parameters granularity (SSC) versus size (FSC) (TreeStar Inc., 
OR, USA). The gating strategy for the flow cytometry analyses are presented on Additional file 1: figure S 1 .

\section{Statistical analysis}

The data was compared by analysis of variance (ANOVA) using Tukey post-test and parametric Student's $t$ test. $p$ values under 0.05 were considered significantly different. Statistical analyses were performed using Prism 8 software (GraphPad Software).

\section{Results}

\section{Clinical signs in infected mice}

Animals infected with PSTV did not show typical clinical signs of infection by virulent strains of VACV, which include piloerection, important weight loss, arched back, swelling of the face, and conjunctivitis. Infection with $10^{6}$ PFU of PSTV led to a slight weight loss on days 6 and 7 post-infection, but animals soon recovered (Fig. 2A). All the mentioned signs were observed in animals infected with GP1V and VACV-WR and their severity were dosedependent. Animals infected with $10^{6}$ PFUs of GP1V lost up to $28.84 \%$ of their initial weight (Fig. 2B) and weight loss in animals infected with $10^{6}$ PFUs of VACV-WR was close to $30 \%$ (Fig. 2C). Mice infected with VACV-WR developed more severe clinical signs when compared to animals infected with the same inoculum of GP1V. These results were similar to data presented on a previous study; such replication was necessary in order to set a baseline for all further experiments and evaluations.

\section{Histopathological analysis of liver, spleen and lung}

The pathological characterization of the lungs, livers and spleens of mice uninfected or infected with $10^{6}$ PFUs of GP1V, PSTV or VACV-WR was performed through the attribution of clinical scores. Scores were given in relation to severity and distribution of the evaluated parameter on the tissue and these values were converted to a total score. For severity and distribution, the scale adopted scores from 0 to 5 or 0 to 4 , in which the maximum value corresponds to a greater severity and distribution of the pathological alteration in the studied tissue. Animals infected with GP1V or VACV-WR developed more intense liver inflammation and degeneration when compared to animals of the control group and to those infected with PSTV (Fig. 3). All infected mice showed higher levels of splenic reactivity (hyperplasia of the splenic white pulp) and pulmonary inflammation when compared to mock-infected animals. Greater levels of oedema and pulmonary haemorrhage were found in the GP1V- and VACV-WR-infected animals compared to the uninfected controls and PSTV-infected animals. The histological findings are consistent with the observed clinical signs.
Splenocyte proliferation after VACV stimulation and characterization of immune cells subpopulations elicited during VACV infection

Proliferation rates of spleen cells were higher in samples from infected mice stimulated with ConA compared to those stimulated with the UV-inactivated VACV-WR (Fig. 4). This increase was similar for splenocytes from GP1V- and PSTV- infected animals and less pronounced for VACV-WR infected animals.

Analyses of subpopulations of splenic immune cells, including T-helper cells, B lymphocytes, NK cells and monocytes from uninfected mice or animals infected with $10^{6}$ PFUs of GP1V, PSTV or VACV-WR were performed (Fig. 5). A reduction in the frequency of $\mathrm{CD} 3+$ cells was observed in the animals from the group infected with VACV-WR and GP1V in comparison to those from the groups infected with PSTV or uninfected (Fig. 5A). A higher statistical significance was found when PSTV-infected or uninfected animals were compared to VACV-WR than when compared to GP1V. Although no differences were detected in the frequency of CD4+ cells in the evaluated groups (Fig. 5B), CD8 + cells were more frequent in groups infected with GP1V and VACV-WR, respectively, in comparison to those infected with PSTV or uninfected controls (Fig. 5C). There was a decrease in the frequency of CD14+and CD3-CD49+ cells in the groups infected with VACV-WR and GP1V when compared to the PSTV and the uninfected control group (Fig. 5D-E). CD14+ subpopulation was even less frequent in animals infected with VACV-WR than in animals infected with GP1V. The unique ability of VACV strains to down-modulate subsets of the host immune cells has been described [10], including for human infections by zoonotic samples of Brazilian VACV [9].

The activation profile of $\mathrm{CD} 8+\mathrm{T}$ cells, observed through the analysis of the expression of the CD28 + molecule, suggested that only animals infected with VACV-WR had a significant reduction in the activation profile of these cells (Fig. 6A). The modulation of $\mathrm{CD} 8+\mathrm{CD} 28+$ cells after infection by the VACVWR virus in mice has been demonstrated previously, as opposed to infections by VACV Lister and modified Vaccinia virus Ankara strains [9]. By analysing B lymphocytes expressing CD80 we observed that the frequency of these cells' subset decreased similarly in mice infected with VACV-WR and GP1V in comparison to animals inoculated with PSTV (Fig. 6B). On the other hand, animals infected with PSTV presented more CD $80+B$ cells than uninfected control animals (Fig. 6B). Compared to the control and PSTV groups, the frequency of CD19+CD86 + cells in animals infected with VACVWR was lower. Similarly, GP1V group showed a significant reduction in these cells compared to PSTV group 


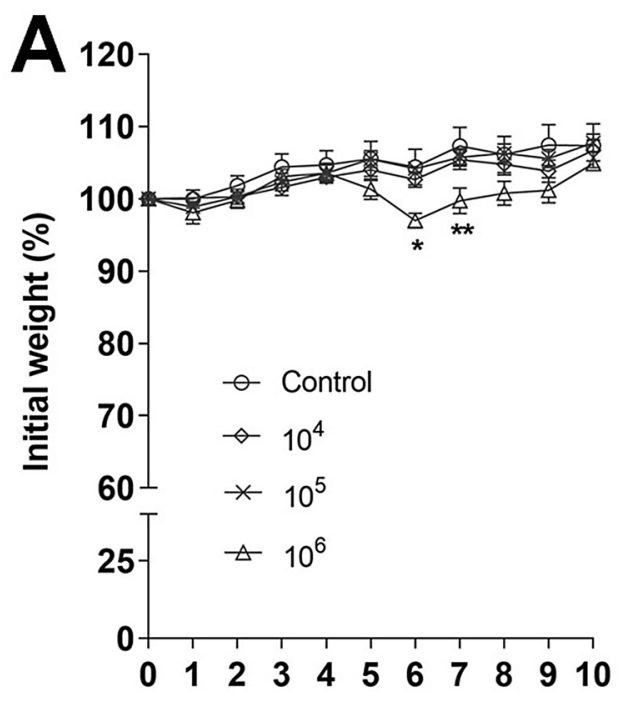

Time p. i. (days)

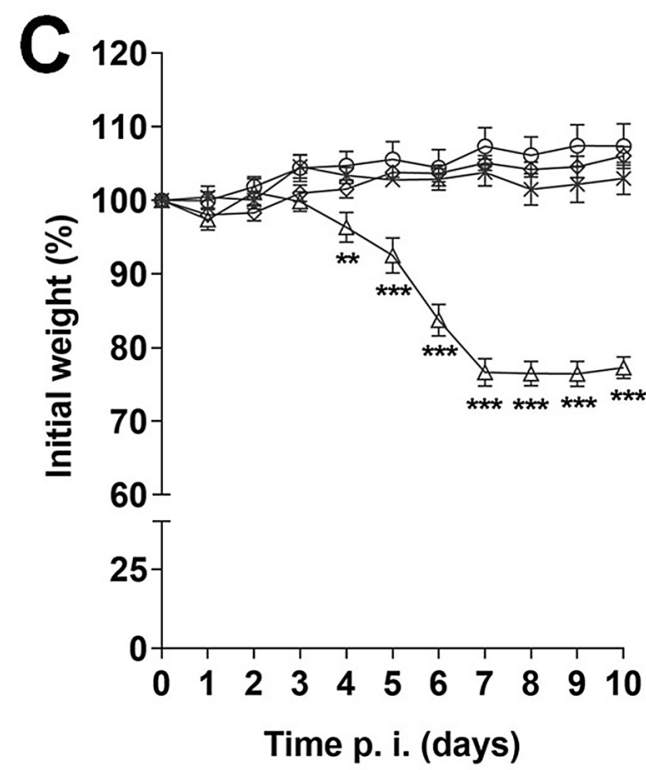

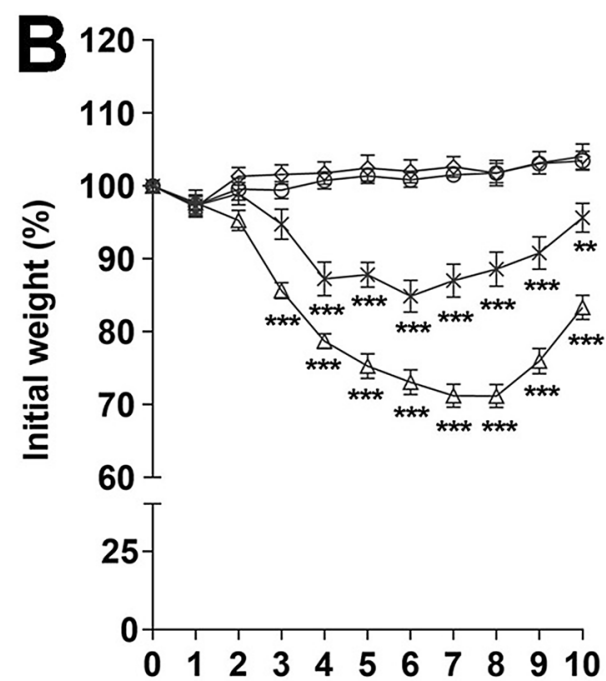

Time p. i. (days)

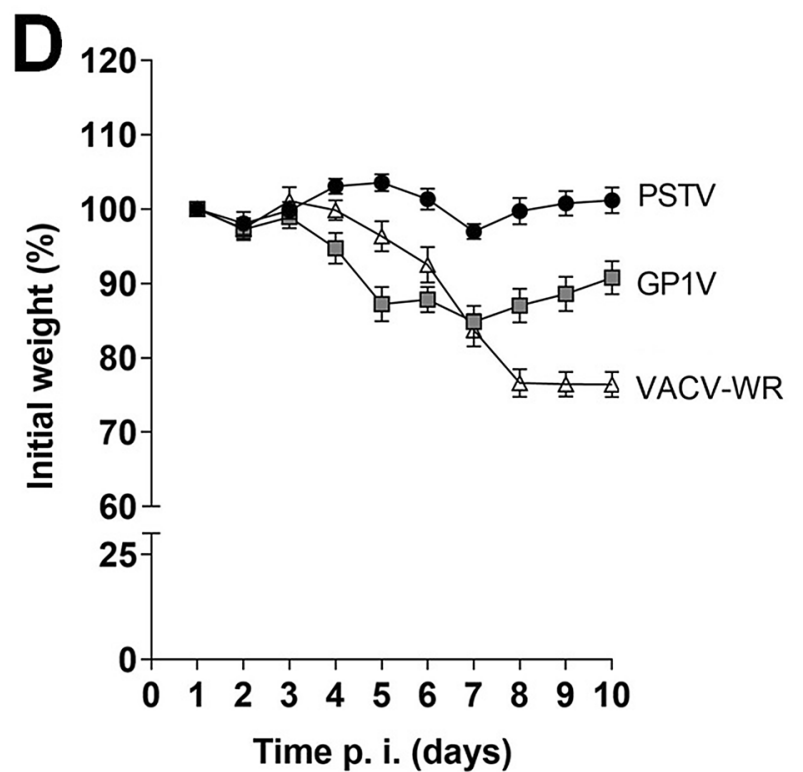

Fig. 2 Body weight of BALB/C mice uninfected or infected with VACV-BR. Groups of mice $(n=5)$ were inoculated with PBS or $10^{4}, 10^{5}, 10^{6}$ PFU of PSTV (A), GP1V (B) or VACV-WR (C) by the intranasal route. Panel D represents the comparative weight loss in animals infected with $10^{6}$ PFU of each one of the three viral samples. The mice's weight was determined daily and those that lost more than $30 \%$ of their initial weight were euthanized. The percentages of median weight relative to their initial weight were plotted. The error bars indicate the standard deviations. Significance variations were calculated using the Two-way ANOVA post hoc Bonferroni with statistical significance: ${ }^{*} p<0.05,{ }^{* *} p<0.01,{ }^{* * *} p<0.001$

(Fig. 6C). This reduction in the frequency of CD80+and CD86 + B lymphocytes was also reported for individuals affected by bovine vaccinia in Brazil [10].

\section{Production of lymphocytic cytokines during infection by different VACV}

We observed a general decrease in the IFN- $\gamma$-producing $\mathrm{CD} 4+\mathrm{T}$ lymphocytes for the infected groups (PSTV,
GP1V and VACV-WR) compared to the uninfected controls, in cells stimulated or not with UV-inactivated VACV-WR (Fig. 7A). The same trend was not observed when the IFN- $\gamma$-producing $\mathrm{CD} 8+\mathrm{T}$ cells were analysed (Fig. 7B). The production of TNF- $\alpha$ by CD $4+\mathrm{T}$ lymphocytes was similar for all groups evaluated after virusantigen stimulation or no stimulation (Fig. 7C). Although the levels of TNF- $\alpha$-producing CD8 + lymphocytes were 

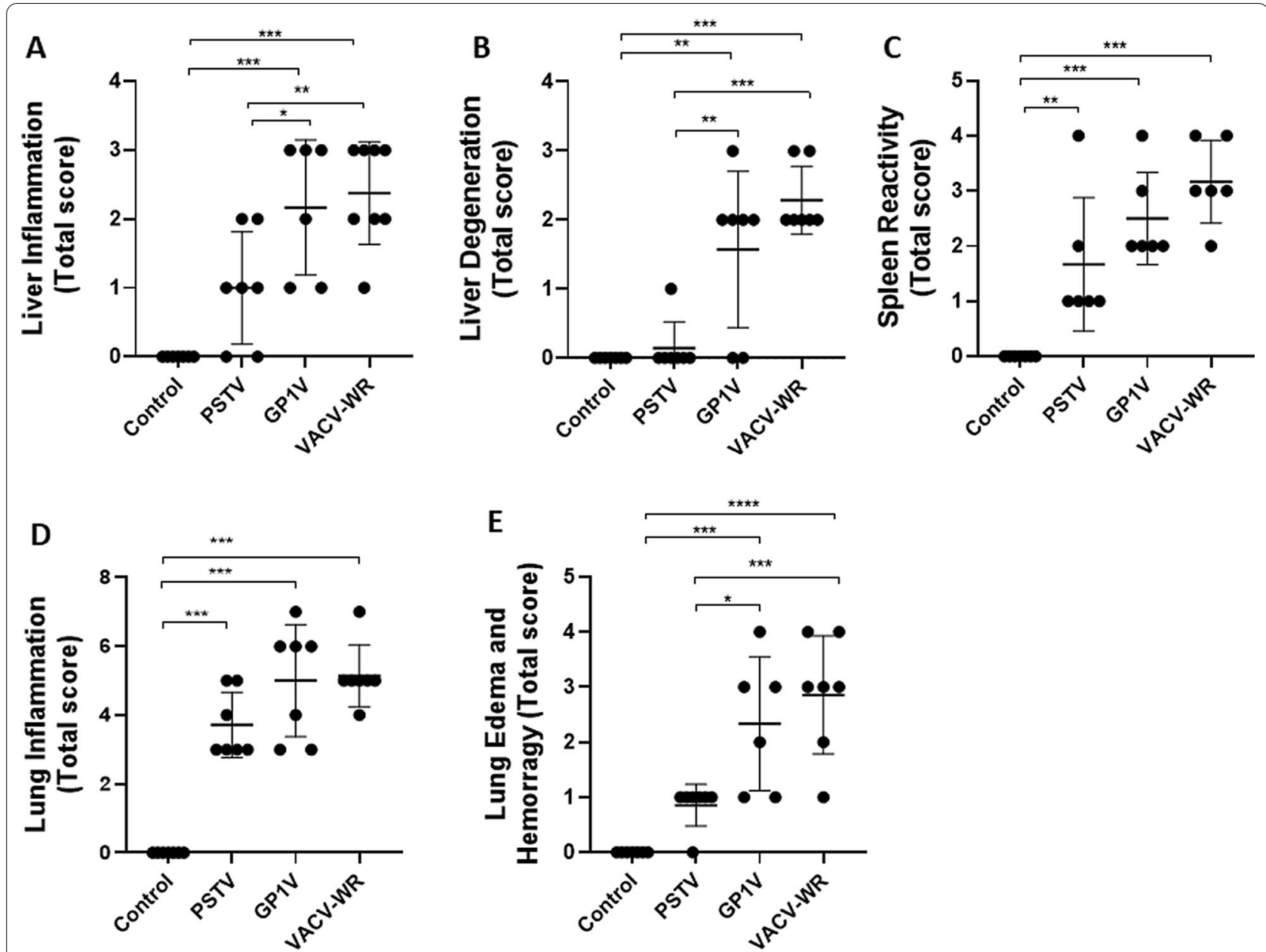

Fig. 3 Pathological analysis of liver, spleen and lung of BALB/C mice uninfected or infected with VACV-BR. Groups of mice $(n=7)$ were inoculated with PBS or $10^{6}$ PFU of PSTV, GP1V or VACV-WR by the intranasal route. The liver inflammation (A) and degeneration (B), spleen reactivity (C), lung inflammation (D), edema and hemorrhage (E) were determined 7 days post infection. Scores were assigned to severity and distribution of the assessed characteristic on the tissue and these values were converted to a total score. For severity and distribution, the scale adopted scores from 0 to 5 or 0 to 4, in which the maximum value corresponds to a greater severity and distribution of the pathological alteration in the studied tissue. The pathological scores were plotted. The error bars indicate the standard deviations. Significance variations were calculated using the One-way ANOVA post hoc Bonferroni with statistical significance: ${ }^{*} p<0.05,{ }^{* *} p<0.01$, ${ }^{* *} p<0.001$

slightly higher in animals infected with PSTV, compared to all other groups, (Fig. 7D) it was clear that the effect of VACV infection in TNF production by T cells is much more subtle than for IFN- $\gamma$ production.

\section{Discussion}

The importance of innate, cellular and humoral immunity components on fighting orthopoxvirus' infections has been demonstrated in several studies. The depletion of macrophages in mice results in their inability to control infection by Vaccinia virus [15]. Likewise, the decline of NK cells levels in C57BL/6 mice culminates in increased ectromelia virus (ECTV) titters and disease severity $[16,17]$. Complement-deficient mice developed more severe disease when infected with cowpox virus [18]. Evaluation of cytokines, such as IFN (I and II) and TNF also confirmed the key role of these molecules in the innate immune response against orthopoxviruses [19-22]. Both cellular and humoral responses are highly coordinated and require the combined activity of $\mathrm{B}$ and $\mathrm{T}$ lymphocytes. The primary infection of mice by ECTV cannot be controlled exclusively by TCD 8 + lymphocytes [23] and production of antibodies by $\mathrm{B}$ lymphocytes is also essential in disease control, reinforcing the functional complementarity of the immune responses upon poxvirus infections. This interaction between $\mathrm{B}$ and $\mathrm{T}$ cells is also crucial in subsequent exposures to these viruses [24]. Nonetheless, 

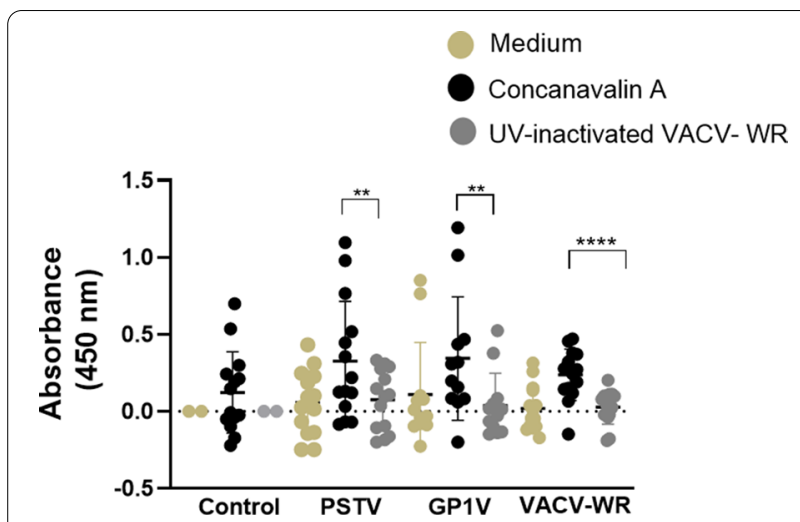

Fig. 4 Proliferation of splenocytes from BALB/C mice uninfected or infected with VACV-BR. Groups of mice $(n=7)$ were inoculated with PBS or $10^{6}$ PFU of PSTV, GP1V or VACV-WR by the intranasal route. The spleen cells proliferation was determined 7 days post infection with BrdU Cell Proliferation Assay (Millipore, EUA) by measuring the absorbance at $450 \mathrm{~nm}$. For that, spleen cells were cultured in the presence of $2 \mu \mathrm{g} / \mathrm{mL}$ of Concanavalin A (black dots), $10^{4} \mathrm{PFU}$ of UV-inactivated VACV-WR (gray dots) or mock-treated with medium (light brown dots). The absorbance values were plotted. The error bars indicate the standard deviations. Significance variations were calculated using the One-way ANOVA post hoc Bonferroni with statistical significance: ${ }^{*} p<0.05,{ }^{* *} p<0.01,{ }^{* * *} p<0.001,{ }^{* * * *} p<0.0001$. During the experiment some animals were lost (The local Committee of Ethics for Animal Experimentation does not allow the replacement of animals to compensate for this loss)

poxviruses encode several proteins that are related to the evasion of the host's immune response [25, 26]. Indeed, it has been demonstrated that poxviruses infecting humans are able to significantly modulate components of host-specific immune response [27, 28]. Likewise, many studies have demonstrated the immunomodulatory ability of poxviruses in animal infections $[9,17,26,29]$. Therefore, these viruses' ability to block, escape or subvert the essential elements of the antiviral response is essential for their replicative success in the host [25].

The Brazilian VACV isolates are currently divided into two distinct groups. This classification considers characteristics such as the virulence of these isolates in a murine model of infection, which in turn is linked to intrinsic genetic differences in their respective genomes [30]. Analyses on how different zoonotic VACV isolates interact with their hosts, as well as other virological and biological aspects, could reinforce and support their segregation and classification into different genetic groups.

In this study, we showed how VACVs that belong to genetically different groups are able to modulate mice immune responses in distinct patterns. Infections with VACV can result in clinical signs such as piloerection, weight loss, back arching, and facial oedema. Nonetheless, animals infected with different VACV isolates show these signs differently $[9,31]$. Ferreira and colleagues have demonstrated that infection by VACV-WR and GP1V in mice led to the appearance of signs such as piloerection, back arching, periocular alopecia and $25 \%$ weight loss. In contrast, the same study showed that animals infected with PSTV and other VACV belonging to group 1, such as the Araçatuba virus and Guarani P2 virus samples, did not exhibit typical clinical signs of the infection and did not experience marked weight loss. We have replicated these experiments and observed that animals infected with GP1V and VACV-WR presented the typical signs of VACV infection belonging to group 2 . On the other hand, mice infected with PSTV showed no obvious clinical signs after virus inoculation.

Poxviruses have an extensive capacity to infect different hosts. However, viral multiplication rates vary according to the host species, considering that it depends on hostspecific antiviral mechanisms [32]. The acute infection initiated in the lung after VACV intranasal inoculation can spread to other organs of the host [31]. One hundred percent of the animals inoculated with the GP1V and VACV-WR showed chronic interstitial pneumonia, however, animals infected with PSTV showed only subtle signs of infection. Liver and spleen were also compromised by infection with viral samples, indicating that PSTV, GP1V and VACV-WR multiply initially in the lungs, spreading to other organs and causing systemic disease. We also found that only VACV-WR was able to cause pulmonary haemorrhage in animals. The histopathological evaluation of the samples showed that PSTV is associated with a lower degree of liver and splenic damage when compared to the other studied viruses (as shown on Fig. 3), similarly to what was described by Ferreira and collaborators [31].

As previously reported, both cellular and humoral immunities are important for controlling infections triggered by orthopoxviruses. Cell proliferation analysis is a parameter to detect the presence of antigen-specific lymphocytes, allowing us to obtain information about the cellular responses induced by the infection. Gomes and collaborators [10] performed cell proliferation experiments in human peripheral blood mononuclear cells (PBMCs) from individuals naturally infected with zoonotic VACV. They observed that after mitogenic and antigenic stimulation, individuals naturally infected with VACV showed a significant proliferative cell response compared to uninfected individuals. Similarly, our results showed increased levels of cell proliferation, after stimulation with VACV-WR, in cells from animals infected with the VACV-WR, GP1V and PSTV samples (Fig. 4).

To deceive the cellular and humoral immune responses, poxviruses encode several proteins capable of modulating their hosts' immune system. Gomes 


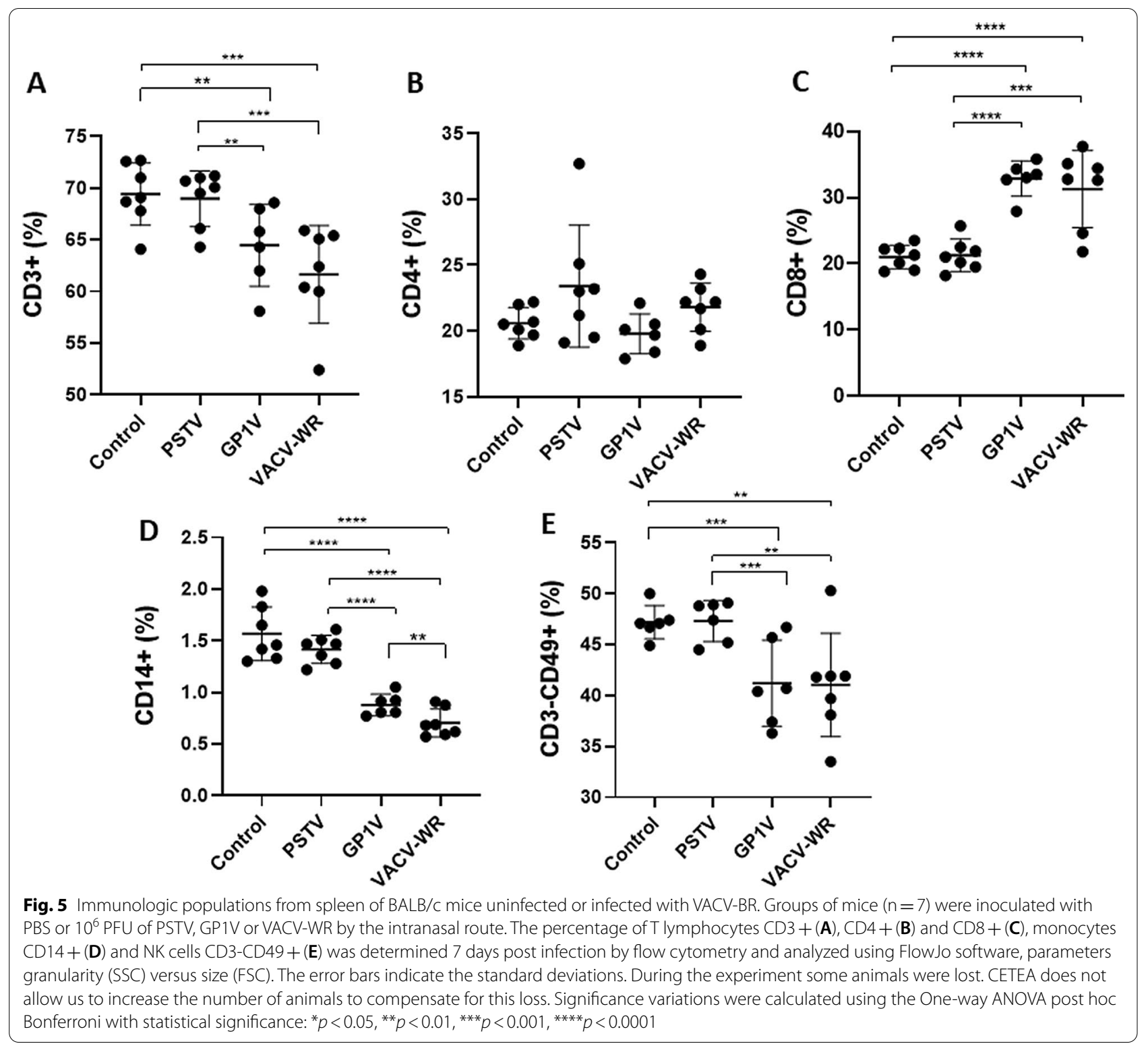

and collaborators [10] showed a lower frequency of CD14+ and an increase in CD8 + in humans infected with VACV zoonotic viruses. The immunomodulation of these subsets of cells suggests that such cells are important in controlling primary infection and preventing viral multiplication in infected cells. Furthermore, several studies have shown that the depletion of CD4 $+\mathrm{T}$ lymphocytes, macrophages and NK cells leads to greater disease severity in mice inoculated with VACV [17, 19, 33]. Overall, these viruses have developed specific down-modulation mechanisms for most immune cells that are important to counter the infection. Our data reflect the differences in patterns of immune responses triggered by different feral VACV strains and different abilities to down-modulate such responses, culminating in distinct patterns of virulence. Infections by the GP1V and VACV-WR viruses (VACV Group 2) resulted in a robust $\mathrm{T} C D 8+$ response, unlike the animals infected with the PSTV sample (VACV Group 1), which presented immune patterns that were similar to those observed in the mock-infected group. Indeed, CD8 $+\mathrm{T}$ cells play an essential role after infection by virulent VACV samples, but against less virulent VACV samples, CD8 + T cells are not so obviously required. [34, 35]. In addition, a reduction in total lymphocytes, NK cells and macrophages were observed in the group infected with VACV-WR. However, once again animals infected with the virus strain belonging 


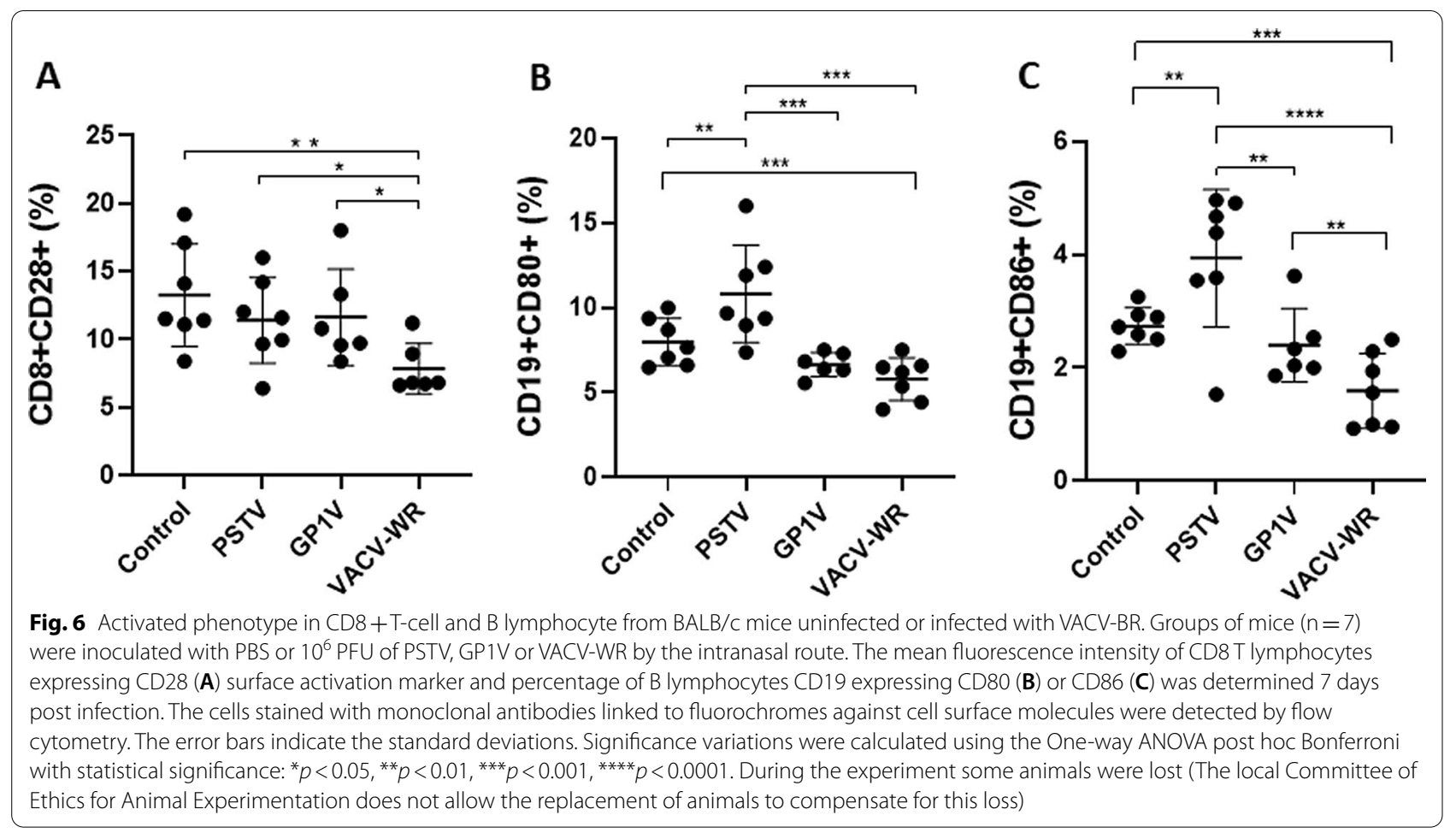

to the phylogenetic group whose virulence characteristics in mice are milder or non-existent did not show variation in these cell subpopulations, presenting a global profile that was similar to the mock-infected animals. Cell activation patterns were also different when different VACV strains were inoculated in mice. VACV-WR- and GP1V-infected animals showed a tendency in CD19+CD80 + cells down-modulation when compared to the uninfected controls. This was also observed in the study of VACV infections in humans [22]. Antibody production by B lymphocytes is essential to control infections caused by VACV [25]; therefore, it is not surprising that these viruses developed countermeasures that inhibit the activation of such cells. Mice infected with VACV-WR showed lower expression of $\mathrm{CD} 28$ in $\mathrm{CD} 8+\mathrm{T}$ lymphocytes when compared to uninfected controls. Similarly, it has been suggested that this molecule is responsible for enhancing the activation of $\mathrm{T}$ cells after infection in mice with this VACV strain [9].

Cytokines are secreted, water-soluble proteins that act as mediators of immune responses, with autocrine and/or paracrine action. VACVs produce virokines and viroceptors that mimic the molecules of the host's immune system, mainly affecting IFN, TNF and other cytokines [36, 37]. IFN- $\gamma$ has several important roles in the host's immune response, acting mainly in the regulation of the adaptive immune response and in the activation of macrophages [38]. Poxviruses encode proteins that are known to counteract IFN production or activity in their hosts [26]. Protein B18 has regions of homology with IFN- $\alpha / \beta$ receptor, and protein B8 is homologous to the IFN- $\gamma$ receptor. These proteins prevent binding of IFN to cellular receptors, emphasizing the importance of this cytokine in the host's response to poxvirus infection $[39,40]$. In addition, the products of the K3L and E3L genes, encoded by vaccinia virus, prevent the inhibition of IFN-induced protein synthesis [41, 42]. It is noteworthy that full genomic sequences for both Brazilian isolates used in this study are not yet available. Nevertheless we can expect these protein-coding genes are conserved in these viruses, considering the high degree of genetic conservation among members of Orthopoxvirus genus [43]. We observed a reduction in IFN- $\gamma$ production by $\mathrm{CD} 4+\mathrm{T}$ lymphocytes in animals infected with GP1V and VACV-WR after antigen stimulation (Fig. 7A). This cytokine participates in the activation of macrophages, stimulation of inflammation and the mounting of Th1type responses, all essential for the control of viral infections [44]. The reduction of IFN- $\gamma$ production by these cells in GP1V- and VACV-WR-infected mice emphasizes the immunomodulatory capacity of these viruses as opposed to the PSTV strain. 

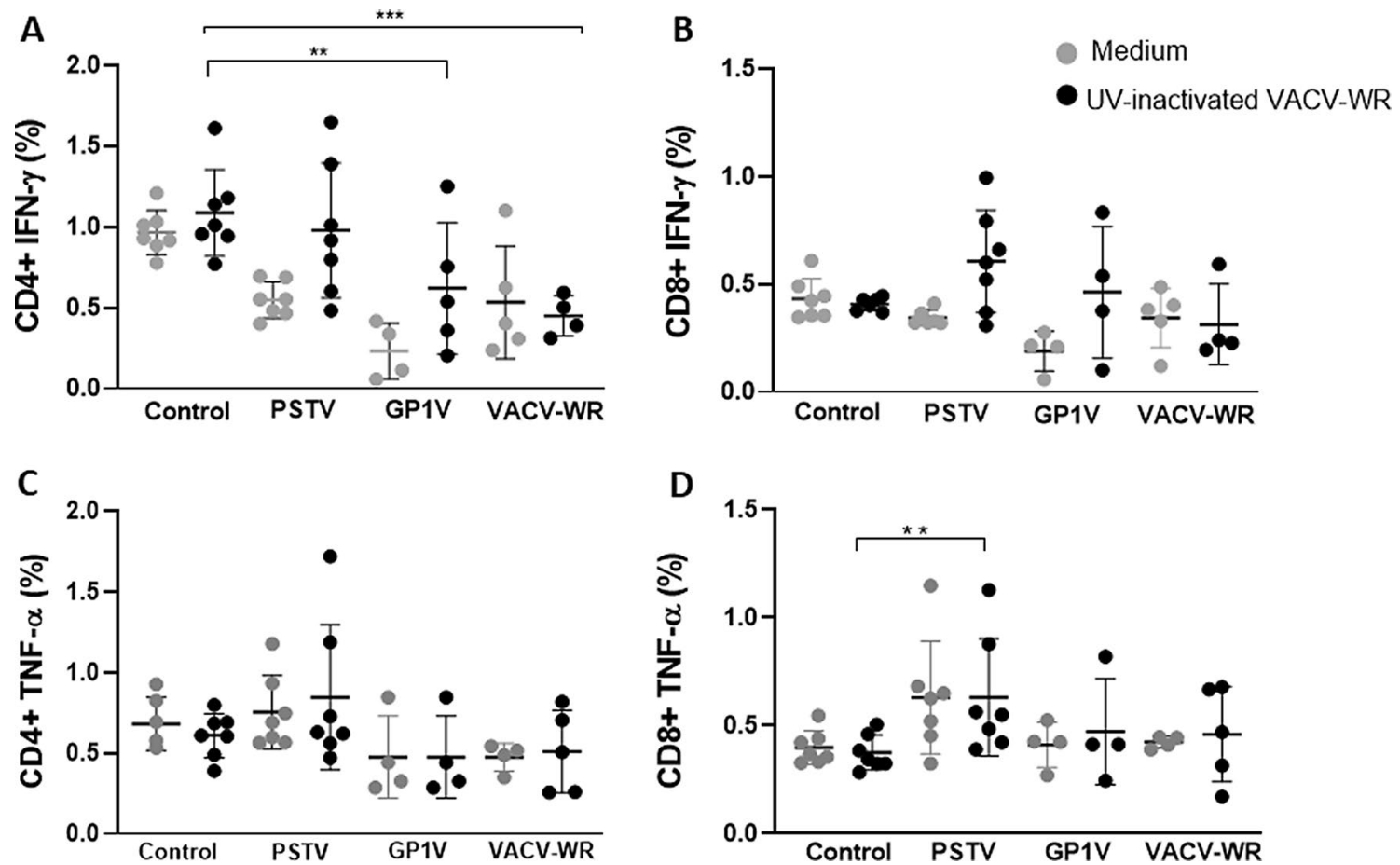

Fig. 7 Interferon-gamma and tumor necrosis factor production from BALB/C mice uninfected or infected with VACV-BR. Groups of mice $(n=7)$ were inoculated with PBS or $10^{6}$ PFU of PSTV, GP1V or VACV-WR by the intranasal route. The percentage of T lymphocytes CD4 + expressing IFN- $\gamma$ (A) and TNF-a $(\mathbf{C})$ or CD8 + expressing IFN- $\gamma(\mathbf{B})$ and TNF-a (D) was determined 7 days post infection by flow cytometry. For that, spleen cells were cultured in the presence of $10^{4} \mathrm{PFU}$ of UV-inactivated VACV-WR (black points) or mock-treated with medium (gray points) and were labeled with mouse anti-IFN- $\gamma$ and anti-TNF- $\alpha$ antibodies. The error bars indicate the standard deviations. Significance variations were calculated using the One-way ANOVA post hoc Bonferroni with statistical significance: ${ }^{*} p<0.05,{ }^{* *} p<0.01,{ }^{* *} p<0.001,{ }^{* * *} p<0.0001$. During the experiment some animals were lost (The local Committee of Ethics for Animal Experimentation does not allow the replacement of animals to compensate for this loss)

\section{Conclusions}

Our data support a model in which the primary immune responses to acute orthopoxvirus' infections have the involvement of Macrophages/Monocytes and possibly $\mathrm{CD} 4+\mathrm{T}$ cells. The observation of modulation of those compartments in both humans [10] and mice, reinforces this hypothesis [12]. Finally, we demonstrated here that zoonotic vaccinia viruses belonging to different clades exhibit immunomodulation properties that are proportional to their pathogenic potential. These observations reinforce the idea that the segregation of zoonotic VACVs in two distinct clade/groups reflects not only genetic differences, but distinct virological and biological aspects as well.

\section{Abbreviations}

BrdU: Bromodeoxyuridine; CETEA: Comitê de Ética em Experimentação Animal; ConA: Concanavalin A; ECTV: Ectromelia virus; FACS: Fluorescence-activated single cell sorting; FSC: Forward scatter; GP1V: Guarani P1 virus; IFN-ү: Interferon; IN: Intranasal; MFF: Macs facs fix; NK: Natural killer; PBMC: Peripheral blood mononuclear cell; PBS: Phosphate-buffered saline; PFU: Plaque-forming unit; PSTV: Passatempo virus; SSC: Side-scattered light; TNF: Tumor necrosis factor; UV: Ultraviolet; VACV: Vaccinia virus; VACV-WR: Vaccinia virus Western Reserve; VACV-BR: Brazilian Vaccinia viruses.

\section{Supplementary Information}

The online version contains supplementary material available at https://doi. org/10.1186/s12985-021-01595-z.

Additional file 1: figure S 1. Gating strategy for the flow cytometry analyses. Although not shown in the figure, analyses of the costimulatory molecules CD25, CD28 and CD86 were conducted using the same strategy.

\section{Acknowledgements}

We thank professor Edel F. B. Stancioli and Jordana G. Coelho-dos-Reis for their expertise and help. We also thank members of the Laboratory of Basic and Applied Virology for their continuing assistance. Special thanks to Thiago L. Leão, for helping with the experiments design and technical assistance.

\section{Authors' contributions}

$\mathrm{KL}$ performed the experiments and analyzed the data, prepared the original draft. LC performed the experiment and helped with the manuscript writing. $\mathrm{LH}, \mathrm{RR}$ and FF designed the experiment and helped with the preparation of the final manuscript. All authors have read and approved the final version of the manuscript. 


\section{Funding}

The Laboratory of Basic and Applied Virology received funds from by CAPES, FAPEMIG and CNPq. FG da Fonseca is a CNPq fellowship recipient. Karine L Lourenço, Leandro A. Chinália, Lethícia R. Henriques, Rodrigo A. L. Rodrigues were CAPES and/or CNPq stipend recipients at the Post-Graduation Program in Microbiology / UFMG.

\section{Availability of data and materials}

Data and materials are available upon request from the corresponding author.

\section{Declarations}

\section{Ethics approval}

All in vivo procedures were approved by the Committee of Ethics for Animal Experimentation (CETEA) from UFMG, under permission 9/2019.

\section{Consent for publication}

Not applicable.

\section{Competing interests}

The authors declare no conflict of interest.

\section{Author details}

'Laboratory of Basic and Applied Virology, Department of Microbiology, Institute of Biological Sciences, Federal University of Minas Gerais, Belo Horizonte, MG, Brazil. ${ }^{2}$ Technical Support Center for Teaching, Research and Extension, Institute of Environmental, Chemical and Pharmaceutical Sciences, Federal University of São Paulo, Diadema, SP, Brazil. ' ${ }^{3}$ Laboratory of Biology and Technology of Microorganisms, Department of Biological Sciences, Federal University of Ouro Preto, Ouro Preto, MG, Brazil. ${ }^{4}$ Laboratory of Viruses, Department of Microbiology, Institute of Biological Sciences, Federal University of Minas Gerais, Belo Horizonte, MG, Brazil.

Received: 19 February 2021 Accepted: 2 June 2021

Published online: 09 June 2021

\section{References}

1. Lefkowitz EJ, Wang C, Upton C. Poxviruses: past, present and future. Virus Res. 2006;117:105-18.

2. Moss B. Poxvirus DNA replication. Cold Spring Harb Perspect Biol. 2013. p. $1-12$.

3. Haller SL, Peng C, McFadden G, Rothenburg S. Poxviruses and the evolution of host range and virulence. Infect Genet Evol. 2014;21:15-40.

4. Da Fonseca FG, Kroon EG, Nogueira ML, De Souza TG. Zoonotic vaccinia virus outbreaks in Brazil. Future Virol. 2011;6:697-707.

5. Drumond BP, Leite JA, da Fonseca FG, Bonjardim CA, Ferreira PCP, Kroon EG. Brazilian Vaccinia virus strains are genetically divergent and differ from the Lister vaccine strain. Microbes Infect. 2008;10:185-97.

6. Trindade GDS, Lobato ZIP, Drumond BP, Leite JA, Trigueiro RC, Guedes MIMC, et al. Short report: isolation of two vaccinia virus strains from a single bovine vaccinia outbreak in rural area from Brazil: Implications on the emergence of zoonotic orthopoxviruses. Am J Trop Med Hyg. 2006:75:486-90

7. Leite JA, Drumond BP, Trindade GS, Lobato ZIP, Da Fonseca FG, Dos Santos JR, et al. Passatempo virus, a vaccinia virus strain. Brazil Emerg Infect Dis. 2005;11:1935-8.

8. Trindade GDS, Drumond BP, Guedes MIMC, Leite JA, Mota BEF, Campos MA, et al. Zoonotic vaccinia virus infection in Brazil: Clinical description and implications for health professionals. J Clin Microbiol. 2007:45:1370-2

9. de Freitas LFD, Oliveira RP, Miranda MCG, Rocha RP, Barbosa-Stancioli EF, Faria AMC, et al. The virulence of different vaccinia virus strains is directly proportional to their ability to downmodulate specific cell-mediated immune compartments in vivo. J Virol. 2018:93:1-16.

10. Gomes JAS, De Araújo FF, Trindade GDS, Quinan BR, Drumond BP, Ferreira JMS, et al. Immune modulation in primary vaccinia virus zoonotic human infections. Clin Dev Immunol. 2012;2012.
11. JoklikWK. The purification of four strains of poxvirus. Virology. 1962;18:9-18.

12. Xu R, Johnson AJ, Liggitt D, Bevan MJ. Cellular and humoral immunity against vaccinia virus infection of mice. J Immunol. 2004;172:6265-71.

13. Kennedy EM, Dowall SD, Salguero FJ, Yeates P, Aram M, Hewson R. A vaccine based on recombinant modified Vaccinia Ankara containing the nucleoprotein from Lassa virus protects against disease progression in a guinea pig model. Vaccine Elsevier Ltd. 2019;37:5404-13.

14. Versiani AF, Astigarraga RG, Rocha ESO, Barboza APM, Kroon EG, Rachid MA, et al. Multi-walled carbon nanotubes functionalized with recombinant Dengue virus 3 envelope proteins induce significant and specific immune responses in mice. J Nanobiotechnol BioMed Central. 2017:15:1-13.

15. Karupiah G, Buller RM, Van Rooijen N, Duarte CJ, Chen J. Different roles for $\mathrm{CD} 4+$ and CD8+ T lymphocytes and macrophage subsets in the control of a generalized virus infection. J Virol. 1996;70:8301-9.

16. Burshtyn DN. NK cells and poxvirus infection. Front Immunol. 2013;4:1-9.

17. Jacoby RO, Bhatt PN, Brownstein DG. Evidence that NK cells and interferon are required for genetic resistance to lethal infection with ectromelia virus. Arch Virol. 1989:108:49-58.

18. Miller CG, Justus DE, Jayaraman S, Kotwal GJ. Severe and prolonged inflammatory response to localized cowpox virus infection in footpads of C5-deficient mice: investigation of the role of host complement in poxvirus pathogenesis. Cell Immunol Cell Immunol. 1995;162:326-32.

19. Karupiah G, Fredrickson TN, Holmes KL, Khairallah LH, Buller RM. Importance of interferons in recovery from mousepox. J Virol. 1993;67:4214-26.

20. Van Den Broek MF, Müller U, Huang S, Aguet M, Zinkernagel RM. Antiviral defense in mice lacking both alpha/beta and gamma interferon receptors. J Virol. 1995;69:4792-6.

21. Haga IR, Bowie AG. Evasion of innate immunity by vaccinia virus. Parasitology. 2005;130.

22. Kennedy RB, Ovsyannikova I, Poland GA. Smallpox vaccines for biodefense. Vaccine. 2009:27:73-9.

23. Fang M, Sigal LJ. Antibodies and CD8 + T cells are complementary and essential for natural resistance to a highly lethal cytopathic virus. J Immunol. 2005;175:6829-36.

24. Panchanathan V, Chaudhri G, Karupiah G. Correlates of protective immunity in poxvirus infection: Where does antibody stand? Immunol Cell Biol. 2008;86:80-6

25. Seet $B T$, Johnston JB, Brunetti CR, Barrett JW, Everett $H$, Cameron C, et al Poxviruses and immune evasion. Annu Rev Immunol. 2003;21:377-423.

26. Smith GL, Benfield CTO, Maluquer de Motes C, Mazzon M, Ember SWJ, Ferguson BJ, et al. Vaccinia virus immune evasion: mechanisms, virulence and immunogenicity. J Gen Virol. 2013;94:2367-92.

27. Shisler JL. Immune evasion strategies of molluscum contagiosum virus [Internet]. 1st ed. Adv. Virus Res. Elsevier Inc.; 2015. https://doi.org/10. 1016/bs.aivir.2014.11.004

28. Rosengard AM, Liu Y, Nie Z, Jimenez R. Variola virus immune evasion design: expression of a highly efficient inhibitor of human complement. Proc Natl Acad Sci USA. 2002;99:8808-13.

29. Rahman MM, McFadden G. Myxoma virus dsRNA binding protein M029 inhibits the type I IFN-induced antiviral state in a highly species-specific fashion. Viruses. 2017:9.

30. Trindade GS, Emerson GL, Carroll DS, Kroon EG, Damon IK. Brazilian vaccinia viruses and their origins. Emerg Infect Dis. 2007;13:965-72.

31. Ferreira JMS, Drumond BP, Guedes MIMC, Pascoal-Xavier MA, AlmeidaLeite CM, Arantes RME, et al. Virulence in murine model shows the existence of two distinct populations of Brazilian Vaccinia virus strains. PLoS ONE. 2008;3:1-10

32. McFadden G. Poxvirus tropism. Nat Rev Microbiol. 2005:3:201-13.

33. Bukowski JF, Woda BA, Habu S, Okumura K, Welsh RM. Natural killer cell depletion enhances virus synthesis and virus-induced hepatitis in vivo. J Immunol. 1983

34. Goulding J, Abboud G, Tahiliani V , Desai P, Hutchinson TE, Salek-Ardakani S. CD8 T cells use IFN- $\gamma$ To protect against the lethal effects of a respiratory poxvirus infection. J Immunol. 2014;192:5415-25.

35. J. Goulding, R. Bouge, V. Tahiliani, M. Croft and SS-A. CD8 T cells are essential for recovery from a respiratory vaccinia virus infection. Bone. 2012;23:1-7.

36. Moss B, Shisler JL. Immunology 101 at poxvirus U: immune evasion genes. Semin Immunol. 2001;13:59-66. 
37. Harrison SC, Alberts B, Ehrenfeld E, Enquist L, Fineberg H, McKnight SL, et al. Discovery of antivirals against smallpox. Proc Natl Acad Sci USA. 2004;101:11178-92.

38. Müller U, Steinhoff U, Reis LFL, Hemmi S, Pavlovic J, Zinkernagel RM, et al. Functional role of type I and type II interferons in antiviral defense. Science 1994;264:1918-21.

39. Colamonici OR, Domanski P, Sweitzer SM, Larner A, Buller RML. Vaccinia virus B18R gene encodes a type I interferon-binding protein that blocks interferon a transmembrane signaling. J Biol Chem. 1995;270:15974-8.

40. Alcamí A, Smith GL. Vaccinia, cowpox, and camelpox viruses encode soluble gamma interferon receptors with novel broad species specificity. J Virol. 1995:69:4633-9.

41. Carroll K, Elroy-Stein O, Moss B, Jagus R. Recombinant vaccinia virus $\mathrm{K} 3 \mathrm{~L}$ gene product prevents activation of double-stranded RNAdependent, initiation factor 2a-specific protein kinase. J Biol Chem. 1993;268:12837-42

42. Chang HW, Watson JC, Jacobs BL. The E3L gene of vaccinia virus encodes an inhibitor of the interferon-induced, double-stranded RNA-dependent protein kinase. Proc Natl Acad Sci USA. 1992;89:4825-9.
43. Hendrickson RC, Wang C, Hatcher EL, Lefkowitz EJ. Orthopoxvirus genome evolution: the role of gene loss. Viruses. 2010;2:1933-67.

44. Farrar MA, Schreiber RD. The molecular cell biology of interferon-gamma and its receptor. Annu Rev Immunol. 1993;11:571-611.

45. Edgar RC. MUSCLE: Multiple sequence alignment with high accuracy and high throughput. Nucleic Acids Res. 2004;32:1792-7.

46. Nguyen L-T, Schmidt HA, von Haeseler A, Minh BQ. IQ-TREE: a fast and effective stochastic algorithm for estimating maximum-likelihood phylogenies. Mol Biol Evol. 2015;32:268-74.

47. Letunic I, Bork P. Interactive tree of life (iTOL) v4: recent updates and new developments. Nucleic Acids Res. 2019;47:256-9.

\section{Publisher's Note}

Springer Nature remains neutral with regard to jurisdictional claims in published maps and institutional affiliations.
Ready to submit your research? Choose BMC and benefit from:

- fast, convenient online submission

- thorough peer review by experienced researchers in your field

- rapid publication on acceptance

- support for research data, including large and complex data types

- gold Open Access which fosters wider collaboration and increased citations

- maximum visibility for your research: over $100 \mathrm{M}$ website views per year

At BMC, research is always in progress.

Learn more biomedcentral.com/submissions 